\title{
AS INFLUÊNCIAS DO MARKETING NA EDUCAÇÃO DE CRIANÇAS PARA O CONSUMO
}

\author{
Mario Sergio Bortolatto \\ André Vanderlin \\ Josué Alberton \\ Fabricio Loch Boeing \\ Simão Enkel Willemann \\ Centro Universitário Barriga Verde - Unibave. Orleans, Brasil \\ Marlene Zwierewicz \\ Universidade Alto Vale do Rio do Peixe - Uniarp. Caçador, Brasil
}

Resumo. O posicionamento das crianças como potenciais consumidores se amplia a medida em que o distanciamento dos pais e/ou responsáveis se torna mais expressivo, facilitando o acesso das empresas de marketing ao público infantil. Tendo como foco essa realidade, esta pesquisa se justifica pela possibilidade que oferece de sistematizar estudos sobre a relação estabelecida entre marketing e o público infantil, utilizando como ferramenta a publicidade realizada por meio de comerciais na televisão. Tem como objetivo apresentar ações do marketing para atingir as crianças, motivando-as ao consumismo, incluindo parâmetros que delimitam a relação entre o público infantil e a propaganda na televisão, a identificação de quais fatores chamam mais atenção das crianças nos comerciais e o conhecimento do tempo médio de contato com a televisão, além de possíveis consequências para o comportamento infantil. Para sua realização, optou-se pela pesquisa bibliográfica e pela abordagem qualitativa, sendo que os resultados apontam para uma ligação da imaginação das crianças com os comerciais. Entre as propagandas de televisão que têm chamado mais atenção do público infantil constam as que fazem uso da temática diversão e incluem personagens infantis. Como as crianças brasileiras são telespectadoras assíduas por mais de cinco horas diárias, ambas as condições são reiteradamente utilizadas nos comerciais.

Palavras-chave: Consumidor, crianças, educação, marketing.

\section{THE INFLUENCE OFMARKETING ON THE EDUCATION OF CHILDREN FOR CONSUMERISM}

\begin{abstract}
The positioning of children as potential consumers broadens as parents and/or legal guardians become more expressively distant, facilitating the access of marketing companies to child viewership. Keeping this reality in focus, the present piece of research is made relevant for the possibility it offers of systematizing studies about the relation established between marketing and child viewers, employing publicity data from TV commercials as tools. The objective of this study, thus, is to present the childrenaimed strategies employed in marketing that seek to motivate them towards consumerism. For that purpose, this study presents (1) the parameters which define the relation between children viewership and television advertisement, (2) the identification of the factors found to most significantly arrest children's attention in commercials, (3) the latest research findings on the average amount of time spent watching television, and (4) the possible effects this exposure may have on child behavior. Moreover, this investigation consists of a qualitative approach to the available literature in the area. The results point to a link between children's imagination and TV commercials, especially those that portray childhoodassociated characters and convey the notion of fun. Once Brazilian children are assiduous TV viewers
\end{abstract}


(over 5 hours of TV exposure a day), both conditions (characters and fun) are overtly and repeatedly used by children-aimed commercials.

Keywords: consumer, children, education, marketing

\section{LAS INFLUENCIAS DEL MARKETING EN LA EDUCACIÓN DE NIÑOS PARA EL CONSUMO}

Resumen. El posicionamiento de los niños como potenciales consumidores se va ampliando a medida en que el distanciamiento de los padres y/o responsables se vuelve más expresivo, facilitando de esa manera el acceso de las empresas de marketing al público infantil. Teniendo esta realidad como enfoque, la relevancia de esta investigación se justifica por la posibilidad que ofrece de sistematizar estudios acerca de la relación establecida entre marketing y público infantil, empleando la publicidad realizada por medio de comerciales de televisión como herramienta. Así, el objetivo de este estudio es presentar acciones del marketing dirigidas a niños que buscan motivarlos al consumismo. Para tal efecto, este estudio presenta (i) parámetros que definen la relación entre el público infantil y la propaganda en la televisión; (ii) la identificación de cuáles son los factores que más llaman la atención de los niños en los comerciales; (iii) conocer cuál es el promedio del tiempo de contacto con la televisión; y (iv) las posibles consecuencias que inciden sobre el comportamiento infantil. Además, para la realización de este estudio optamos por una investigación bibliográfica y adoptar el enfoque cualitativo. Los resultados sugieren que hay una conexión entre la imaginación de los niños y los comerciales. Entre las propagandas de televisión que más llaman la atención del público infantil se encuentran las que hacen uso de la temática de diversión y que incluyen personajes infantiles. Ya que los niños brasileros son televidentes asiduos, es decir más de cinco horas diarias, se utilizan reiteradamente ambas condiciones en los comerciales dirigidos a niños.

Palabras clave: consumidor, niños, educación, marketing.

\section{Introdução}

A influência da sociedade na formação das pessoas é uma condição histórica e permeia também a realidade atual. Ao analisar essa condição, Durkheim (1973) enfatizou que a existência da vida depende de um ambiente natural, no qual cada indivíduo se entrelaça com as necessidades básicas de seu grupo.

O desenvolvimento de cada pessoa, portanto, depende da existência e necessidades de seu grupo. Essa relação de dependência influenciará na formação individual e será acompanhada por uma pressão social, priorizando valores de cada período histórico. Nesse processo, fatores externos, valorizados socialmente, tendem a transformar-se em necessidades para o indivíduo.

Viana, Bastos e Loyola (2010) reforçam que a sociedade possui seus próprios valores, absorvidos pelos indivíduos desde o nascimento, para que possam se reconhecer no coletivo. Nesse sentido, o indivíduo se constitui a partir de influências externas, apesar de contribuir também para as mudanças na sociedade.

Ao destacar a relevância da interação no desenvolvimento humano, Fernandes e Zanelli (2006) afirmam que, do ponto de vista social, a ordem que se estabelece, ou não, resulta do compartilhamento nesse processo, enquanto no âmbito individual a identidade se encontra em relação dialética com a sociedade. Nesse sentido, cada pessoa é produto, mas também produtor do sistema social. 
Em seu desenvolvimento, portanto, uma série de fatores contribuirá para constituição do perfil do futuro adulto, entre elas o meio familiar, escolar e virtual. Em decorrência, o perfil da criança formado no mundo atual é diferente do perfil da criança da década de 1970, por exemplo, quando uma parte significativa dos pais trabalhava em ambientes externos enquanto as mães desempenhavam o trabalho mais próximas aos filhos.

Na década de 1970, o acesso aos meios de comunicações no Brasil era reduzido, limitando-se basicamente ao rádio e, de forma menos expressiva, à televisão. Naquela época, empresas de publicidade utilizavam crianças com a função de interlocutoras para estimular os adultos como possíveis consumidores. Contudo, Araújo (2016) reforça que a inovação no âmbito tecnológico, impulsionada a partir da década de 1980, estimulou que as empresas percebessem que as próprias crianças poderiam representar uma importante fatia do mercado consumidor.

Tal condição foi potencializada pela ampliação de domicílios com acesso à televisão no contexto brasileiro, cujo percentual passou de $24 \%$ na década de 1970 para 87\% em 2000 (Mendonça e Anjos, 2004). Na Figura 1 é possível observar que o índice foi ampliado em anos subsequentes.

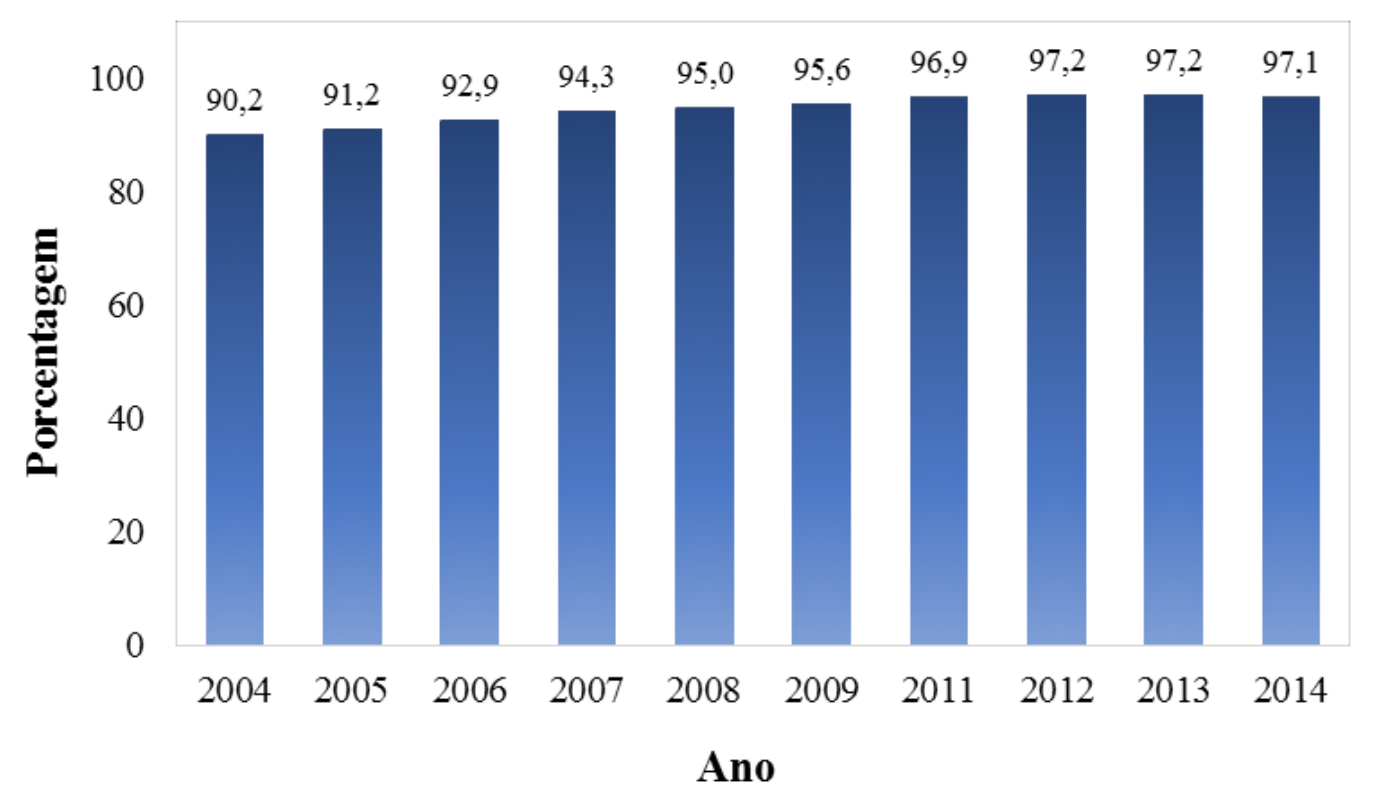

Figura 1. Proporção de domicílios particulares permanentes no Brasil com acesso à televisão Nota: Fonte: Adaptado de IBGE (2015)

"Percebe-se que a posse de televisão já se encontrava bastante disseminada em 2004, mas continuou se expandindo gradualmente até 2011. Entre 2011 e 2014, a proporção de domicílios particulares permanentes com televisão permaneceu estável" (IBGE, 2015, p. 109). Apesar dessa estabilidade, o alto percentual contribuiu para que a publicidade atingisse massivamente a população brasileira.

Em contrapartida, a mudança nos hábitos dos consumidores, com exigências por qualidade no atendimento e agilidade na entrega do produto, iniciou logo após a segunda guerra mundial (Viana, Bastos e Loyola, 2010). Como consequência desse novo perfil consumidor, as empresas perceberam que o não atendimento das necessidades dos clientes poderia dificultar a aceitação de seus produtos no mercado, desencadeando uma nova forma de competitividade comercial, revertendo na migração 
das empresas de uma orientação focada em vendas para uma direção voltada ao marketing (Schiffman e Kanuk, 2000).

$\mathrm{O}$ marketing de comunicações é um conjunto de atividades voltado para atingir massas populacionais. Seu objetivo é conseguir mudanças no conhecimento, atitudes, comportamento de um grupo inteiro em relação a um determinado produto ou serviço (Hradiská e Letovancová, 1998).

Sua eficiência é ampliada com estudos de comportamento dos consumidores, cujos resultados são utilizados pelas empresas para que as pessoas responsáveis pelo departamento de marketing possam direcionar seus produtos ao público alvo. É nesse ínterim que o marketing atinge as crianças.

Viana, Bastos e Loyola (2010) alertam que a criança, no seu processo de formação cognitivo, desenvolve capacidades de interação com o ambiente e absorção de informações à sua volta. Em poucos anos, passa a ser um espectador ativo dos conteúdos ofertados pela mídia, fazendo plena distinção de programações como comercial, desenho e notícia. Os autores também afirmam que a criança absorve a informação como tal e aos poucos se identifica como consumidor, sendo que "A sociedade de consumo e a sociedade de lazer se encontram indissociavelmente vinculadas, o que faz com que as crianças desde sempre reconheçam seu papel de consumidor. Além do mais, elas se espelham em adultos, que frequentemente dedicamse a acumular bens materiais e de consumo." (Viana, Bastos e Loyola, 2010, p. 123).

Evidentemente, em qualquer mercado é de fundamental importância compreender os fatores ou motivos que influenciam os clientes na compra de um produto. Todas as pessoas irão consumir algum produto, em determinado momento de suas vidas, seja por necessidade ou por desejo efêmero. Além disso, o comportamento do consumidor pode ser influenciado por fatores como a classe socioeconômica, faixa etária, cultura e estilo de vida. No caso do público infantil como espectador do contexto social onde está inserido, pode gerar uma premissa de necessidade do produto apresentado na mídia e, desta maneira, o âmbito global passa a criar seus valores no indivíduo.

Considerando as implicações midiáticas no comportamento infantil, esta pesquisa se justifica em função da capacidade que oferece para sistematizar estudos sobre a relação estabelecida entre consumo, marketing e o público infantil, utilizando como ferramenta a publicidade realizada por meio de comerciais na televisão. Para tanto, apresenta ações do marketing para atingir as crianças, motivando-as ao consumismo, bem como o entendimento da relação existente entre o público infantil e a propaganda na televisão, a identificação de quais fatores chamam mais atenção em um comercial de televisão e o conhecimento do tempo médio de contato com a televisão, bem como prováveis consequências.

Espera-se que os resultados colaborem para melhorar a formação infantil, estimulando que o entendimento de que a criança é um sujeito social e histórico e que tem uma natureza singular, que a caracteriza como um ser que sente e pensa "... o mundo de um jeito muito próprio." (Brasil, 1998, p. 21), venha acompanhada por processos de ensino e de aprendizagem que estimulem a reflexão e a consciência diante do paradoxo consumo - preservação da vida.

\section{Método}

No sentido de analisar a ação do marketing no comportamento das crianças, optou-se pela pesquisa bibliográfica e pela predominância da abordagem qualitativa, ainda que se selecionaram também alguns dados quantitativos. Essa opção foi 
justificada pela possibilidade oferecida para o atendimento dos objetivos propostos na pesquisa.

A pesquisa bibliográfica se assegura pela coleta de dados culturais ou científicos realizada sobre um determinado assunto, tema ou problema (Marconi e Lakatos, 2001, Cervo e Bervian, 2002, Oliveira, 2011). Para Marconi e Lakatos (2001, p. 183) a pesquisa bibliográfica “... abrange toda bibliografia já tornada pública em relação ao tema estudado, desde publicações avulsas, boletins, jornais, revistas, livros, pesquisas, monografias, teses, materiais cartográficos, etc.... e sua finalidade é colocar o pesquisador em contato direto com tudo o que foi escrito, dito ou filmado sobre determinado assunto."

A abordagem qualitativa, por sua vez, trabalha os dados buscando seu significado. Capta a aparência do fenômeno estudado, tentando explicar sua origem e mudanças. Esse mesmo autor nos mostra que a pesquisa qualitativa busca, nesse sentido, definir “... uma espécie de representatividade do grupo maior dos sujeitos que participarão no estudo. Porém, não é, em geral, a preocupação dela a quantificação da amostragem. E, ao invés da aleatoriedade, decide intencionalmente, considerando uma série de condições (sujeitos que sejam essenciais, segundo o ponto de vista do investigador, para o esclarecimento do assunto em foco; facilidade para se encontrar com as pessoas; tempo do indivíduo para as entrevistas, etc.)." (Triviños, 1987, p.132).

Como fonte de pesquisa foram analisados materiais utilizados nos comerciais destinados ao público infantil, bem como artigos científicos, livros, sites de internet, teses de doutorado e trabalhos de conclusão de curso. Destacaram-se como fontes de pesquisas, as situadas na sequência:

- O estudo de Andrade (2010, p. 177): enfatiza “... a luta pelo reconhecimento da condição da criança como sujeito de direitos, em especial a uma educação infantil de qualidade que assegure a ela a sua condição de ser criança e sujeito protagonista nos espaços institucionais." ;

- O estudo que envolveu comunicações de marketing de fabricantes de alimentos voltadas para crianças e a mídia internet, quando os dados empíricos foram coletados em duas etapas. "... A primeira, observacional, serviu para identificar marcas de alimentos infantis com website. Na segunda, analisou-se o conteúdo de sites identificados na etapa anterior, aproveitando o codificador de um estudo similar realizado nos Estados Unidos. Os resultados abrangem cinco temas: perfil nutricional, jogos, downloads, marketing viral e alertas. Implicações, ao final, são elaboradas tanto para a formulação de políticas públicas quanto para a gestão de comunicações de marketing." (Huertas, Urdan, Adachi e Gomes, 2012, p. 79);

- A tese de doutorado do Departamento de Psicologia e Educação da Universidade de São Paulo, realizada por Nascimento (2006, p. 11), apresentando a influência da televisão nos hábitos alimentares de crianças e adolescentes, onde foi “... evidenciado que a televisão anuncia elevada frequência de propagandas de alimentos ... e que, ... tais fatores poderiam estar influenciando os hábitos alimentares de crianças e adolescentes, contribuindo para o aumento nos índices de obesidade.";

- O Trabalho de Conclusão de Curso do Departamento de Teoria e Prática da Educação da Universidade Estadual de Maringá, realizada por Louza (2012, p. 6), mostrando a influência da mídia no consumo infantil, onde foi “... investigado como as propagandas televisivas, direcionadas ao público infantil, influenciam o consumo do mesmo, tornando as crianças consumidoras precoces.";

- O artigo científico de Viana, Bastos e Loyola (2010, p. 117) que discutem a relação estabelecida entre “... criança, consumo e propaganda, por meio de apresentação de 
tópicos sobre o assunto. Além disso, buscou-se esclarecer a importância, hoje, dos estudos sobre comportamento do consumidor, apresentar a noção da criança inserida num contexto social e discorrer sobre o comportamento do consumidor criança e a forma como ela assimila a propaganda.

\section{Resultados e discussão}

Os resultados, apresentados na sequência, foram delimitados por meio das seguintes variáveis: relação entre o público infantil e a propaganda na televisão, a identificação de fatores que mais chamam a atenção das crianças nos comerciais,o tempo médio de contato com a televisão e suas possíveis consequências para o comportamento infantil.

\section{Público infantil e a propaganda na televisão}

Além de contextualizar como o mercado se relaciona com os clientes, destaca-se também o comportamento desse mesmo mercado em relação ao público infantil. Para tanto, recorreu-se ao estudo realizado por Viana, Bastos e Loyola (2010) para observar a interação da criança com o entorno durante o desenvolvimento cognitivo, inserindo a televisão nesse processo. Para eles:

A criança, ao longo de seu desenvolvimento cognitivo, desenvolve a capacidade de interação com o ambiente e de absorção das informações à sua volta. Ela absorve progressivamente os ensinamentos dos pais e também os conteúdos ofertados pela mídia. Em poucos anos a criança já se inicia como espectador ativo, aprendendo a estabelecer conexões importantes sobre as operações físicas e pragmáticas da televisão e logo cedo percebem que não podem exercer nenhuma influência sobre o conteúdo apresentado. (2010, p. 122).

Esse novo público, em partes, é mais complicado de ser previsto, pois é mais difícil de analisar uma criança que não sabe exatamente o que quer e motivo dela querer, que um adulto convicto. Mais próximo à pré-adolescência, contudo, as crianças têm mais segurança de suas necessidades, sem deixar seus desejos materiais de lado. A compreensão por parte das crianças em relação à propaganda, certamente irá ser diferente de acordo com sua faixa etária, mas em geral é a partir dos 8 anos que elas chegam nessa fase, passando a formar certo senso crítico.

Estudo realizado por Karsaklian (2004) mostrou que aos 3 anos de idade as crianças optam entre um programa e outro; $82 \%$ das crianças de 4 anos sabem a diferença entre propaganda e programa de televisão; e aos 6 anos de idade esse número sobe para $98 \%$; isso acontece devido ao fato de a criança reconhecer que a propaganda é mais curta e engraçada que os programas.

As crianças, em especial, têm grande tendência de serem influenciadas ao consumismo, condição que pode levá-las a terem características e perfis de consumidores na vida adulta, reproduzindo vivências que elas tiveram nessa fase de suas vidas. Karsaklian (2004) elaborou, de forma resumida, um tipo de cronologia a respeito das vivências às quais as pessoas podem estar submetidas:

- De 0 a 6 anos: produtos individuais que lhes dizem respeito diretamente; 0 a 2 anos: mais rejeição do que solicitação sobre brinquedos e comida que são mostrados; 2 a 4 anos: primeiras solicitações em relação a roupas, livros e discos; 4 a 6 anos: as preferências são mais acentuadas;

- De 7 a 11 anos: ampliação dos centros de interesse em direção a produtos familiares; 7 a 8 anos: os pedidos são mais precisos e cada vez mais orientados para produtos familiares utilizados; 9 a 11: compras familiares, como automóveis, férias ou equipamentos, e surgimento de desejos por produtos para adultos; 
- De 12 a 14 anos: a criança entra na idade do especialista e se focaliza sobre um número reduzido de centro de interesse e torna-se imbatível em certas áreas (motos, carros, informática...). Seu universo se reorganiza em torno de especialidades mais centralizadas.

Para alcançar os resultados esperados - que seria a influência sobre as crianças -, as propagandas de qualquer gênero, seja por meio da televisão aberta, rádios, jornais, entre outros meios de comunicação, devem criar uma ponte que as faz alcançar as fantasias e desejos, conduzindo-as por um sonho. O uso dessas fantasias, dessa realidade surreal, pode ser justificado pela possível rejeição das crianças aos problemas do cotidiano. Em contrapartida, o envolvimento dos sonhos das crianças proporciona para elas um ambiente mais familiar, algo que as deixem mais confortáveis e despertem um maior nível de interesse.

Outros fatores, percebidos por Karsaklian (2004), Montigneaux (2003) e Viana, Bastos e Loyola (2010) podem contribuir para fidelizar a clientela infantil:

- As crianças desejam que a propaganda as divirta. Se ela conseguir fazê-las rir, o primeiro obstáculo terá sido superado;

- As propagandas ricas em ação são muito apreciadas, bem como aquelas que põem em evidência valores que são importantes para as crianças de cada idade (ser forte, ser inteligente, ser o bom amigo, ser o herói da turma...);

- Uma boa música ou um ritmo atraente costuma favorecer o interesse das crianças pela propaganda;

- Para ser eficaz, uma propaganda de produtos infantis precisa dirigir-se não somente à criança, mas também aos pais;

- Colocar prêmios em determinada propaganda não implicará, necessariamente, uma atitude da criança de trocar sua marca favorita porque outra lhe oferece prêmios.

Conforme apresentado pelos autores, a ligação com o mundo imaginário da criança é fundamental para estabelecer uma relação de 'conquista' entre o consumo e suas necessidades. Contextualizar o que se está apresentando ao mundo infantil dentro do mundo vivenciado pela criança é a chave para alcançar um 'bom resultado'. A criança demonstra ser alguém ligada à sua imaginação, despertando nela um sentimento de satisfação.

Nesse sentido, as opções de relação com o mundo infantil variam de idade para idade, mas o importante é manter a relação com a vivência do imaginário. Percebe-se, também, que a relação com os pais é de grande importância, especialmente, no sentido de gerar uma aprovação para o que seu filho esteja visualizando, evitando a não aceitação em visualizar e, consequentemente, consumir.

Não há uma fórmula, ou alguma teoria que dê exatidão para que as empresas utilizem um método de vendas eficaz, mas algumas ferramentas podem auxiliar a nortear as empresas para que atinjam seus objetivos. Em contrapartida, Karsaklian (2004) afirma que as crianças não estão aptas para decidir sobre caro ou barato, certo ou errado, e por esses e outros motivos as propagandas que são direcionadas para o público infantil podem receber várias críticas.

No Brasil, estudos realizados por Huertas, Urdan, Adachi e Gomes (2012, p. 85) mostraram que "Em um nível mais específico, há o código de defesa do consumidor (Lei Federal $\mathrm{N}^{\circ}$. 8.078/90) e o estatuto da criança e do adolescente (Lei Federal $\mathrm{N}^{\circ}$. 8.069/90)." Enquanto o “... Código regulamenta a prática de propaganda e outras ações de marketing, vedando abusos", o “... estatuto, protege em vários âmbitos, fazendo menção pontual à publicidade." Existe também a regulamentação do próprio setor, por meio do Conselho de Auto-Regulamentação Publicitária (CONAR), que delimita os 
termos da propaganda para crianças. Todavia, as vedações cobrem só uma das ferramentas de comunicação de marketing, a propaganda (por vezes referida como publicidade).

\section{O que chama a atenção das crianças em uma propaganda?}

As propagandas e o marketing, de forma geral, têm a finalidade de vender a imagem de algum produto ou serviço. Para isso, podem se utilizar do bom senso como também podem utilizar de alguns recursos não tão adequados, com o fim de proporcionar nos clientes uma influência de compra. As propagandas dirigidas às crianças, portanto, podem ser consideradas, às vezes, abusivas pelo fato de se utilizarem da ingenuidade delas, já que acreditam facilmente nas coisas que ouvem; elas também acreditam no marketing e nas propagandas, como se realmente aquele produto que ela está sendo influenciada a comprar irá atender suas expectativas, seus sonhos.

A TNS/InterScience realizou, em 2003, uma pesquisa e revelou que em média uma criança influencia em até $80 \%$ as decisões de compra da família brasileira (Luccas, 2009). Para que as crianças não se tornem consumidores compulsivos, é necessária uma atenção especial, principalmente, por parte dos pais.

Educar implica sempre, em maior ou menor grau, a necessidade de limitar, de às vezes dizer não, de negar algumas coisas aos filhos. Dizer não nessas circunstâncias pode se tornar uma coisa difícil, para muitos, talvez uma barreira intransponível (Zagury, 2010, p. 24).

Louza (2012) diz que a publicidade vem focando as crianças como principais consumidores, pelo menos desde a década de 1990. Fala ainda, que a regra para convívio social está diretamente ligada aos produtos que aquele grupo consome, utiliza, e as propagandas não perdem tempo quando se trata de influenciar uma compra. A partir desse ponto de vista é possível observar que o consumismo passa a ser uma prática social.

Para o público infantil, esse tipo de influência pode levar a elas informações sobre os padrões culturais da sociedade de forma geral. Isso pode fazer com que as crianças tenham uma opinião formada, mas que já teve uma influência por parte do marketing.

Estudos mostraram que bastam cerca de 30 segundos para uma marca influenciar a criança, sendo diversos os canais com programas direcionadas ao público infantil que exibem propagandas que influenciam as compras; assim, a criança torna-se o indivíduo principal no consumo familiar (Gonçalves, 2009). Além disso, as crianças conseguem ter grande influência dentro da casa em relação a tudo o que é comprado. Esse poder de influência da criança acaba encontrando no sentimento de culpa dos pais um importante aliado, pois os mesmos, ao se ausentarem por períodos muito longos de tempo, acabam tentando 'compensar' sua ausência com produtos difundidos pelos comerciais (Louza, 2012).

\section{Tempo de contato da criança com a televisão e prováveis consequências}

Para abordar propaganda e marketing é fundamental se tratar também da televisão, pois é um dos principais meios de comunicação de uso das empresas para fazer propagando de seus produtos e serviços. Além disso, o público infantil é um grande consumidor deste meio de comunicação.

"Segundo levantamento do Ibope 2011, as crianças brasileiras estão entre as que mais assistem à televisão no mundo, com uma média superior a 5 horas por dia." (Agência Brasil, 2012). Essa grande exposição acarreta problemas como mais consumo de energia, sedentarismo das crianças e, evidentemente, influencia muito o consumismo. 
Destaca-se também que pesquisas têm evidenciado os produtos alimentícios quando são analisados programas de marketing em sistemas de comunicação. A Figura 2 registra os principais produtos que as crianças consomem, sendo que a grande maioria são produtos industrializados.

De acordo com publicação do Instituto Alana (2014), realizada no site criança e consumo, “... 33\% das crianças brasileiras têm excesso de peso, 15\% já são obesas e até 2030 quase metade da população adulta estará acima do peso". Considerando-se a média superior a 5 horas de exposição diária das crianças à televisão (Agência Brasil, 2012), as propagandas que incentivam o consumo de alimentos não saudáveis podem ter influência na obesidade infantil ao apresentar-lhes mensagens ilusórias como: 'coma e fique mais bonito', 'como e fique mais inteligente' ou 'coma e fique tão forte como os super-heróis'.

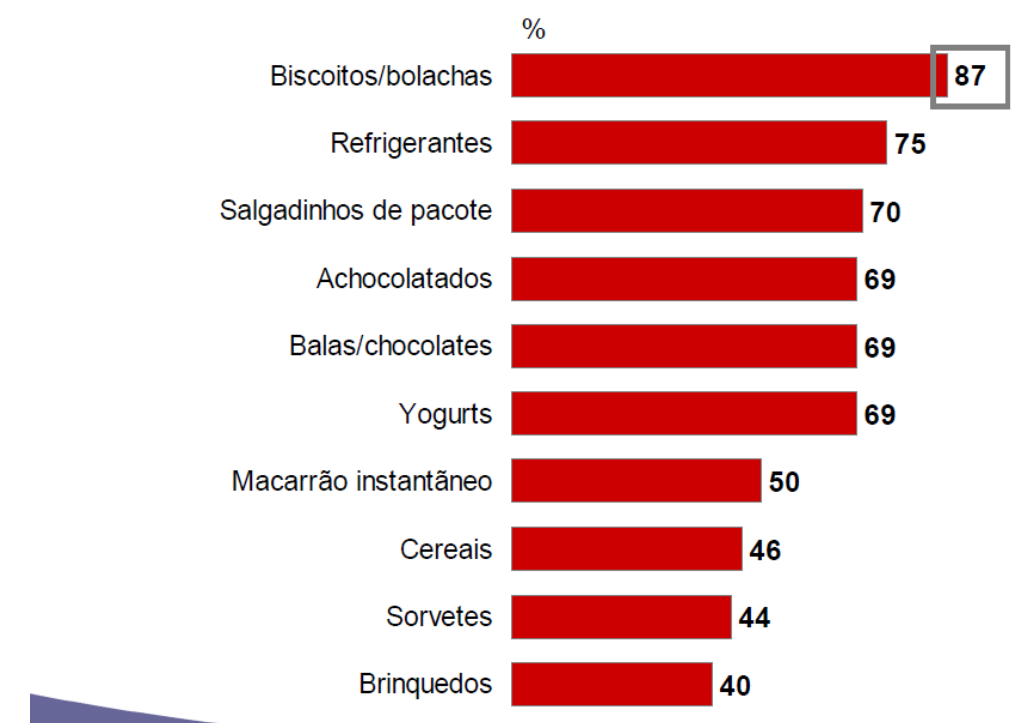

Figura 2. Produtos mais pedidos pelas crianças

Nota: Fonte: InterScience (2003)

Conforme apresentado na Figura 3, pesquisa mostrou também que as crianças têm grande influência tanto na compra de produtos pelos pais como também nas marcas escolhidas. 


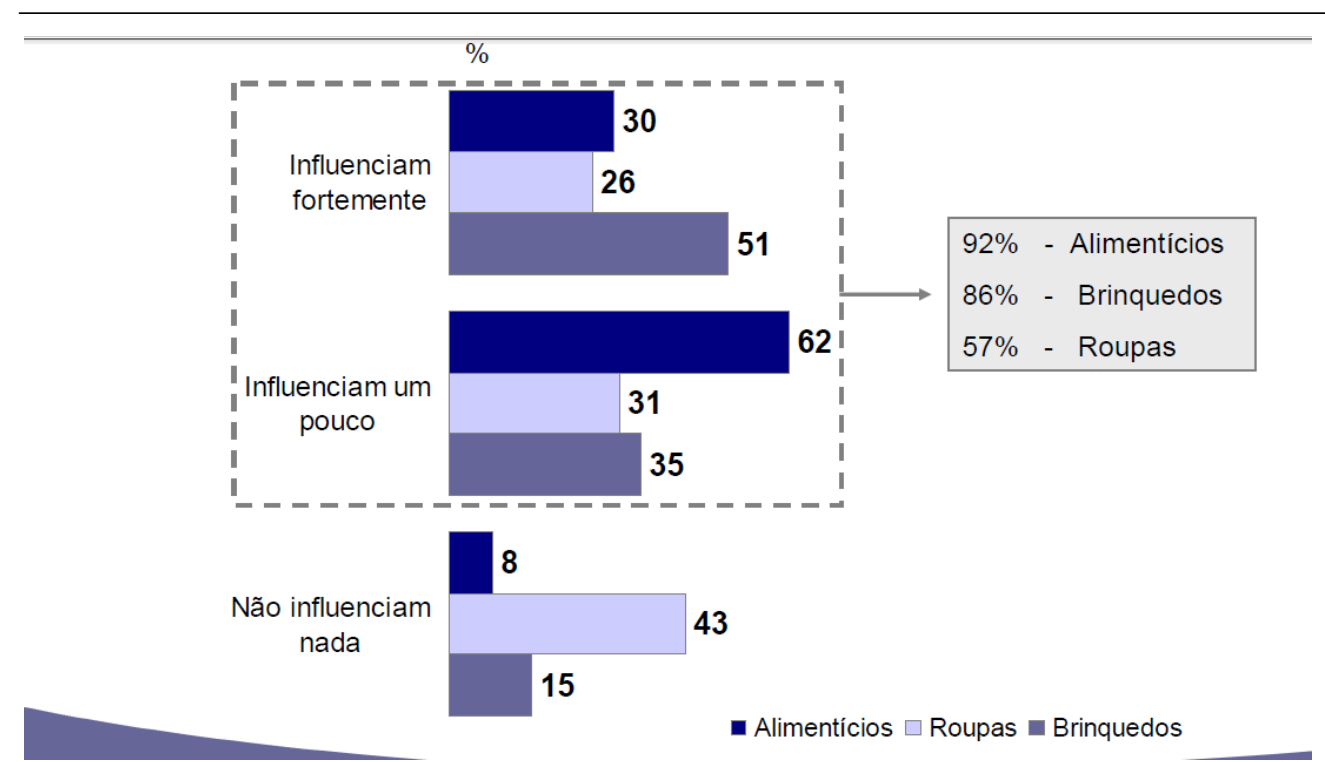

Figura 3. Influência das crianças nas compras Nota: Fonte: InterScience (2003)

As crianças representam fonte de influência aos consumidores, bem como elas se tornam fortes consumidoras. As pesquisas mostraram, ainda, que a principal influência causada pelas crianças como consumidoras é no segmento alimentício. As crianças possuem uma capacidade de envolvimento psicológico delas com seus cuidadores, onde estes apresentam tendência de atender a pedidos por se sensibilizarem com o apelo dos mesmos.

A Figura 4 apresenta um cenário prevendo o crescimento da influência do público infantil na tomada de decisão em relação ao processo de seleção da marca do produto.

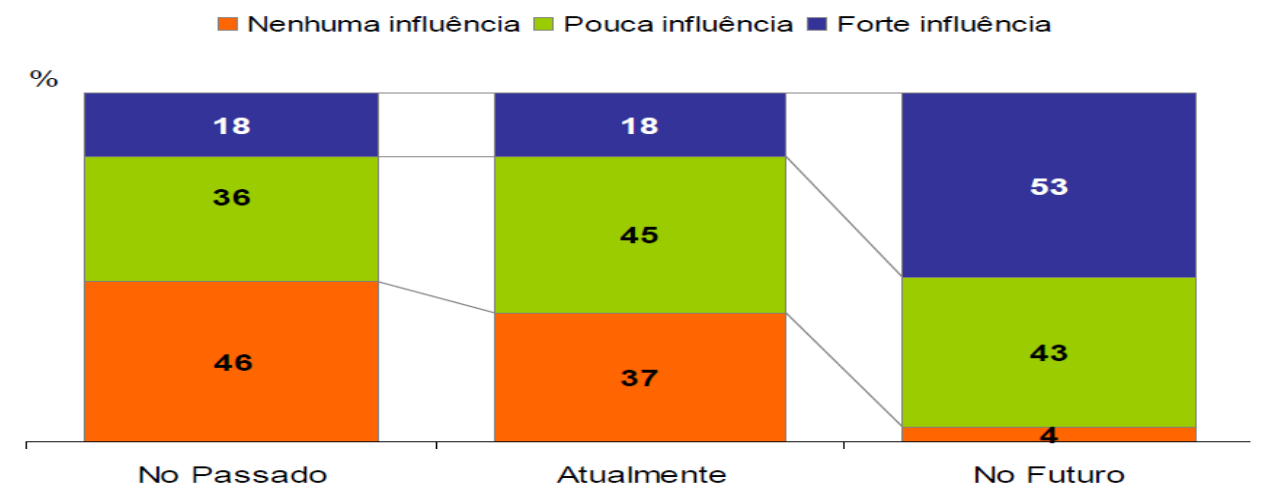

Figura 4. Influência das crianças na escolha das marcas em geral Nota: Fonte: InterScience (2003)

Grande parte das propagandas infantis apresentam personagens e produtos conjugados e, geralmente, esses personagens consomem ou utilizam o produto durante a propaganda. Conforme relata o psicólogo Albert Bandura, o ser humano relaciona seu aprendizado na imitação (Blanco, Bonvecchio e Trak, 1997). Dessa maneira, as propagandas fazem uso desse conhecimento para intensificar o aumento do consumo dos produtos (Nascimento, 2006).

Propagandas que utilizam personagens infantis com o objetivo intrínseco de incentivar o consumo de algum tipo de produto são exemplos clássicos usados para chamar atenção do público infantil. Fato esse corroborado por Kotler (2011), quando 
mostra que as crianças acabam sendo influenciadas por meio de instituições de ensino, convívio social e por toda essa tecnologia presente no mundo, que está cada vez mais acessível ao público infantil.

A disponibilidade do acesso cada vez mais comum das crianças a outros meios virtuais de comunicação como a internet, tem levado empresas e marcas de produtos a desenvolverem novas formas de propagandas para serem utilizadas em desktops, notebooks, tablets, smartphones, entre outros dispositivos. $\mathrm{O}$ recurso é o tradicionalmente conhecido, ou seja, a aquisição de um determinado produto fica vinculada com algum tipo de prêmio. No caso da plataforma digital direcionada ao público infantil, em geral, as empresas fazem uso de artifícios como o acesso a jogos eletrônicos vinculados a cupons obtidos somente com a compra do produto. Neste contexto, Huertas (2012) enfatiza de maneira objetiva o exemplo dos produtos alimentícios que apresentam divulgação na internet, onde mostra que aproximadamente $46 \%$ das empresas nesse seguimento possuem site específico com programas de entretenimento infantil, como, jogos, animações, personagens e promoções.

\section{Conclusões}

Um projeto de marketing lançado para o público infantil requer estratégias diversificadas a fim de abranger áreas infantis e adultas. Nesse interim, os pais se tornam peças fundamentais no desenvolvimento dos planos de marketing ao longo da história, especialmente pela redução da presença na vida de seus filhos, facilitando a ação dos desenvolvedores que captam condições que minimizam a ausência. Dessa forma, se oportunizam da ausência e aproveitam para ampliar o contato das crianças com os sistemas de comunicação.

Nesse ínterim, consideram a necessidade de ligar a imaginação do público infantil com os comerciais. Para isso, empresas de marketing têm se utilizado de ícones do meio infantil, sendo eles, principalmente, personagens de desenhos animados, buscando trabalhar a ideia de relação positiva destes personagens com o produto apresentado.

A principal relação encontrada está envolvida entre personagens de destaque e produtos alimentícios. Levando-se em consideração o potencial do público infantil, existe grande possibilidade que as empresas elevem as ações de marketing sobre este seguimento de mercado. Além disso, o breve envolvimento psicológico do tema apresentou a relação de estratégias de marketing e estudos voltados à Psicologia, buscando um envolvimento entre estes dois profissionais.

Como o presente trabalho apresentou a ação do marketing no comportamento das crianças, sugere-se que novos estudos sejam realizados para conhecer com maior profundidade as estratégias de empresas em relação ao público infantil em segmentos específicos, além de estratégias didáticas que podem ser usadas nas escolas para chamar a atenção dos pais no sentido de valorizar a aproximação com seus filhos, bem como trabalhar a conscientização em relação às práticas de marketing e o estímulo ao diálogo antes da efetivação de qualquer compra.

\section{Referências}

Agência Brasil (2012). Campanha estimula criança a doar brinquedo antigo. [S. 1]: O Popular. Recuperado de http://www.ebc.com.br/2012/10/campanha-estimulacrianca-a-doar-brinquedo-antigo, em 27 de janeiro de 2016. 
Andrade, L. B. P. (2010). Educação infantil: discurso, legislação e práticas institucionais. São Paulo: Cultura Acadêmica.

Araújo, F. (s. d.). Influência da publicidade no desenvolvimento da criança. Recuperado de http://www.infoescola.com/comunicacao/influencia-da-publicidade-nodesenvolvimento-da-crianca/, em 17 fevereiro de 2016.

Blanco, B., Bonvecchio, A. e Trak, M.A. (1997). Influencia de los medios de comunicación en los hábitos alimentarios Del venezolano, Publicitemos los alimentos con ética, Anales Venezolanos de Nutrición, 44-57.

Brasil (1998). Referencial curricular nacional para a educação infantil/Ministério da educação e do desporto, secretaria de educação fundamental. Brasília: $\mathrm{MEC} / \mathrm{SEF}$.

Cervo, A. L. e Bervian, P.A. (2002). Metodologia científica. São Paulo: Prentice Hall.

Durkheim, E. (1973). Educación y Sociología. Buenos Aires: Editorial Shapire.

Fernandes, K. R. e Zanelli, J. C. (2006). O processo de construção e reconstrução das identidades dos indivíduos nas organizações. Revista de Administração Contemporânea, 10 (1), 55-72.

Gonçalves, T. A. (2009). A publicidade dirigida a crianças e a formação de valores. IV Encontro Mulheres em Movimento: 20 anos.

Hradiská, E., e Letovancová, E. (1998). Psychológia v marketingovej komunikácii. Bratislava: UK.

Huertas, M. K. Z., Urdan, A. T., Adachi, P. P. e Gomes, S. C. (2012). Comunicações de marketing de fabricantes de alimentos: quando o alvo são Crianças e a mídia internet. Revista Gestão \& Tecnologia, 12 (3), 79-102.

InterScience (s. d.). Como atrair o consumidor Infantil, atender expectativas dos pais $e$ ainda, ampliar as vendas. Recuperado de http://criancaeconsumo.org.br/wpcontent/uploads/2014/02/Doc-09-Interscience.pdf, em 27 de março de 2016.

Karsaklian, E. (2004). Comportamento do consumidor. São Paulo: Atlas.

Kotler, P. (2000). Administração de marketing: análise, planejamento, implementação e controle. São Paulo: Prentice Hall.

Louza, F. P. P. (2012). A influência da mídia no consumo infantil. Trabalho de conclusão de curso, Universidade Estadual de Maringá, Maringá.

Luccas, J. (2009). Um freio a publicidade infantil. Revista Cidade Nova, 1, 14-18.

Marconi, M. de A. e Lakatos, E. M. (2001). Fundamentos de metodologia científica. São Paulo: Atlas.

Mendonça, C.P., Anjos, L.A. (2004). Aspectos das práticas alimentares e da atividade física com determinantes do crescimento do sobreposto/obesidade no Brasil. Cadernos de Saúde Pública, 20 (3), 698-709.

Montigneaux, N. (2003). Público-alvo: Crianças - A força dos personagens e do marketing para falar com o consumidor infantil. Rio de Janeiro: Campus.

Nascimento, P.C.B.D (2006). A influência da televisão nos hábitos alimentares de crianças $e$ adolescentes. Tese de doutorado, Universidade de São Paulo, Ribeirão Preto. 
Oliveira, M.F. de (2011). Metodologia científica: um manual para a realização de pesquisas em administração. Catalão: UFG.

IBGE (2015). Síntese de indicadores sociais: uma análise das condições de vida da população brasileira. Rio de Janeiro: IBGE, Coordenação de População e Indicadores Sociais.

Instituto Alana (s. d.). Custo com obesidade no país é de 2,4\% do PIB. Recuperado de http://criancaeconsumo.org.br/noticias/custo-com-obesidade-no-pais-e-de-24do-pib/, em 29 de março de 2016.

Schiffman, L. G.; Kanuk, L. L. (2000). Comportamento do consumidor. Rio de Janeiro: LTC.

Triviños, A. N. S. (1987). Introdução à pesquisa em ciências sociais: a pesquisa qualitativa em educação: o positivismo, a fenomenologia, o Marxismo. São Paulo: Atlas.

Viana, F., Bastos, T. e Loyola, V. (2010). A propaganda e as crianças: um estudo dos argumentos utilizados pelos comerciais e a reação do público infantil aos estímulos. Medição, 12 (11), 117-128.

Zagury, T. (2010). Limites sem trauma, construindo cidadãos. Rio de Janeiro: Record.

Data de recebimento: $16 / 06 / 2016$

Data da revisão: $20 / 03 / 2017$

Data do aceite: 03/05/2017 
